\title{
ANÁLISE ÉTICA FRENTE À OMISSÃO ESTATAL NO CASO DE ÚRSULA BAHILLO
}

\author{
ETHICAL ANALYSIS AGAINST STATE OMISSION IN THE CASE OF ÚRSULA BAHILLO
}

\author{
Giovanna Assen Sampaio de Souza
}

Universidade Federal de Roraima, Boa Vista, RR, Brasil. E-mail: giovannaassen@gmail.com

\section{Juliana Fabrícia Correia Oribuela}

Universidade Federal de Roraima, Boa Vista, RR, Brasil. E-mail: julianaorihuela@gmail.com

\section{Melissa Eduarda Moreira Mendes}

Universidade Federal de Roraima, Boa Vista, RR, Brasil. E-mail: melissaeduarda1@hotmail.com

\section{Douglas Verbicaro Soares}

Universidade Federal de Roraima, Boa Vista, RR, Brasil. E-mail: douglas_verbicaro@yahoo.com.br

DOI: https://doi.org/10.46550/amormundi.v2i5.108

Recebido em: 30.07.2021

Aceito em: 18.08.2021

\begin{abstract}
Resumo: $\mathrm{O}$ ano de 2021 iniciou, para as mulheres argentinas, como mais um motivo de resistência feminina. Úrsula Bahillo era o nome da jovem argentina de 18 anos, que dentre tantas outras, foi vítima de violência por seu ex-companheiro após denunciá-lo diversas vezes. Através de investigação em artigos, noticiários e pesquisa de dados o presente estudo depreende a deturpação do conceito da ética e a negligência do Estado Argentino como grandes fatores para o assassinato de Ursula. O estudo conlui pela existência de práticas discriminatória de gênero no país argentino e a necessidade de discussão social sobre ações de proteção ás vítimas dessa violência.
\end{abstract}

Palavras-chave: Gênero. Proteção. Violência. Mulher.

Abstract: The year 2021 began, for Argentine women, as another reason for female resistance. Ursula Babillo was the name of the 18-year-old Argentine girl, who, among many others, was the victim of violence by her former partner after denouncing him several times. Through research in articles, news and data research, this study decants the misrepresenting of the concept of ethics and the negligence of the Argentine State as major factors for Ursula's murder. The study was based on the existence of discriminatory gender practices in the Argentine country and the need for social discussion on actions to protect victims of this violence.

Keywords: Gender. Protection. Violence. Woman. 


\section{Introduçáo}

$\bigcup_{\text {de } 2021 \text { teve o infeliz final nas máos do seu ex-companheiro e foi mais uma vítima }}^{\text {rsula Bahillo era como se chamava a jovem argentina de } 18 \text { anos. Em } 08 \text { de fevereiro }}$ do feminicídio no país. O autor do crime, Matías Martínez, de 25 anos, exerce serviço policial na província de Buenos Aires e está entre tantos profissionais da segurança pública argentina que assassinam suas companheiras, ex-companheiras e familiares (LLORENTE, 2021).

Figura 1: Úrsula Bahillo

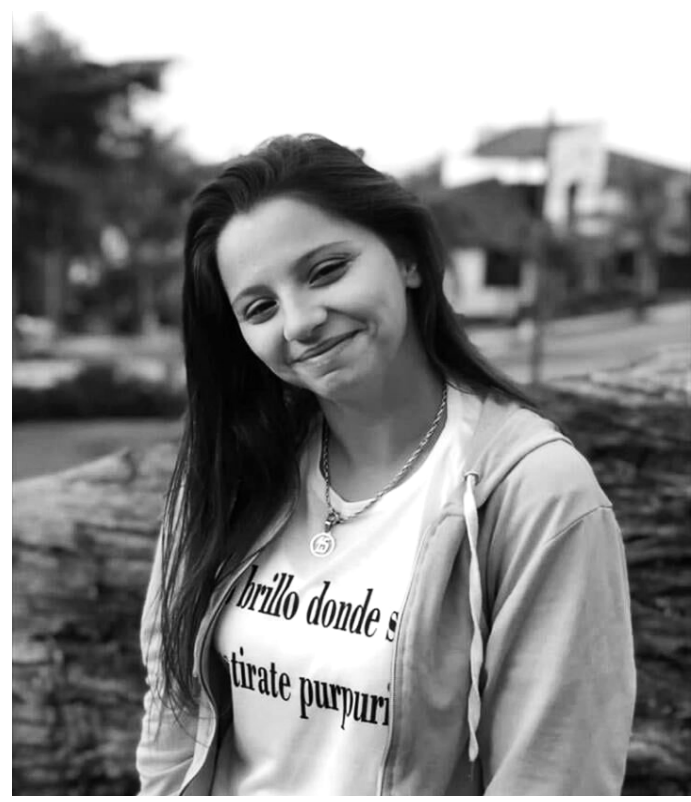

Fonte: Graciela Nassuti para BBC, 2021

"Não posso mais, amiga, não posso mais, estou muito triste. Ele disse que vai me matar [...] Não aguento mais, quase quebrou a minha mão, não consigo mexer meu pulso. Quero ir embora daqui. Estou com muito medo" disse Bahillo à uma amiga em novembro de 2020 (CENTENERA, 2021).

Úrsula não foi a primeira a ser agredida e vítima do machismo de Martínez. O referido ingressou na segurança de Buenos Aires em 2015 e foi afastado logo depois, em 2018, devido às inúmeras denúncias de violência de gênero acumuladas, sendo reintegrado no ano de 2020. Em setembro do mesmo ano em que voltou ao exercício, o policial recebeu licença psiquiátrica, isso porque a junta médica definiu a inaptidão deste em servir nas forças, haja vista a quantidade de denúncias em seu nome (LUCOTTI, 2021).

O canal de comunicação SPUTNIK informa que por 18 (dezoito) vezes a jovem pediu ajuda ao Estado, sendo as últimas: duas em janeiro e uma em fevereiro de 2021. Contudo, o juiz de paz Luciano Callegari rejeitou as denúncias e assegurou que o agressor não era perigoso. Por insistência a mãe de Úrsula foi à Delegacia da Mulher no dia 6 de fevereiro, dois dias antes da morte da jovem, entretanto teve seu depoimento ignorado pois era fim de semana (LUCOTTI, 2021).

Apesar de não confirmadas pelas autoridades judiciais, as 18 (dezoito) reclamaçôes são mencionadas por grande parte da mídia. Destas, o promotor do caso, Sergio Manuel Terrón, reconheceu apenas 6 (seis), pois apresentam-se com tramitação na justiça (DELFINO, 2021). 
Em defesa das acusaçóes por populares, o juiz Callegari, em entrevista, informou que foi responsável por 3 (três) das denúncias de violência sofridas por Úrsula, sendo a primeira apresentada no dia 09 de janeiro pela mãe de Úrsula (DELFINO, 2021). Nesta, o magistrado afirma que ordenou medida de restrição de perímetro de 200 metros e proibição de contato por outros meios. Ainda, afirmou ter determinado a entrega do botão anti-pânico à Bahillo (DELFINO, 2021).

Alguns pontos são divergentes entre os noticiários, mas todos chegam a um mesmo final e trazem uma mesma conclusão: uma morte evitável.

O promotor do caso informou que na manhã do dia 08 de fevereiro, data da morte, Martínez havia sido intimado pela Ayudantía Fiscal de Rojas quanto à imposição de uma medida protetiva que vedava sua aproximação à Úrsula (CIJUR, 2021). Todavia, conforme a transcrição de áudios e mensagens, há de se entender que o agressor e a vítima marcaram um encontro à tarde - considerada, pelo promotor, uma manipulação vivida por Úrsula, que não podendo se livrar das ameaças, parecia dever explicaçóes quanto às denúncias que realizou (CIJUR, 2021).

O encontro aconteceu e Martínez dirigiu com Úrsula à bordo a um local a cerca de 10 quilômetros da cidade de Rojas, com grandes árvores e um rio. Nesse momento, o policial a atacou, transformando Úrsula Bahillo em mais uma vítima do feminicídio na Argentina (CIJUR, 2021).

Três dias antes de seu assassinato, Úrsula havia denunciado que estava sendo ameaçada de morte por Martínez, momento em que solicitou o botão antipânico (TELAM, 2021). Após análise dos relatórios policiais, foi observado que no dia do ocorrido, o juiz Callegari havia determinado a entrega do instrumento de segurança, contudo, ninguém abriu o e-mail com o comunicado e o botáo chegou tarde demais (TELAM, 2021).

O que assegurava a vida de Úrsula Bahillo? Qual apoio legal ela tinha frente às ameaças que sofria? Ela foi uma dentre quantas que sofreram e tiveram as vidas ceifadas na Argentina? Onde está posto o machismo? E o Estado Argentino, foi útil na tentativa de salvar essa vida?

Para o trabalho foi pensada uma pesquisa multidisciplinar dando destaque, principalmente, a uma investigação por noticiários nacionais e internacionais que relatam a história de Bahillo, dados de violência e através do direito positivo argentino em busca de explicaçôes. $\mathrm{O}$ trabalho foi dividido em quatro seçôes principais. A primeira retrata o cenário de violência contra as mulheres no país. A segunda versa sobre a legislação argentina de segurança à violência de gênero. A terceira parte aborda a culpa do Estado Argentino quanto à sua omissão no caso de Úrsula Bahillo. A última seção, por fim, vislumbra a ideia modificada do ser ético ocasionada pelo machismo social e institucional, refletindo em grande perigo à vida das mulheres na Argentina, seguida das consideraçôes finais e referências.

\section{0 cenário de violência contra mulheres na Argentina}

A violência de gênero se faz presente na sociedade há um longo período, demonstrando ser um fenômeno complexo a cada correlação com o período histórico, a região, o sistema político, social e econômico vivido (CEGATTI, 2018, p. 11). Verifica-se que, historicamente, a imposição de papéis de gênero na sociedade, com pesos e níveis diferentes, promoveu reaçóes de violência, em razão da percepção de domínio e poder do homem sobre a mulher (LIMA, 2017. 
p. 05).

Diante disto, o feminicídio se sobressai em um contexto patriarcal como a expressão máxima da violência de gênero, após uma vivência feminina, em regra, de privações, opressóes e violências físicas, psicológicas, verbais e/ou sexuais, em suma perpetradas por pessoas com quem estas mantêm vínculos afetivos (CARDOSO, 2018).

Ante o exposto, na ambientação latino-americana a recorrência contínua dessas violaçôes, refletem a existência de um problema muito mais latente e de longa duração (LIMA, 2017, p. 05). A América Latina demonstra ter um dos maiores índices do mundo de crimes contra as mulheres, de acordo com dados do Observatório de Igualdade de Gênero da América Latina e do caribe (OIG), "todos os dias morrem cerca de 12 mulheres latino-americanas, apenas pelo fato de serem mulheres" (BBC, 2016).

As sociedades latinas possuem resquícios do patriarcado herdado do período colonial, e portanto, o cenário Argentino segue o mesmo modelo. Contudo, o tema tem sido mais amplamente debatido nos últimos anos diante da visibilidade de diversos casos de feminicídios brutais que não haviam tido amparo estatal, mesmo diante de denúncias (CARDOSO, 2018).

Em face disto, com aumento da mobilização social, tais como o movimento "Ni una a menos", e, consequentemente, a maior contabilização dos casos, os números de feminicídios argentinos chocam pelos altos números em relação a demografia do país (CENTENERA, 2020). Apesar de ser um dos países latinos com taxas de homicídios relativamente baixas, os feminicídios vêm crescendo nos últimos anos e demonstra ser a principal causa de mortes dolosas de mulheres argentinas (LEGRAND et al, 2020, p. 05).

Conforme estudo promovido pela FRIEDRICH-EBERT-STIFTUNG, o homicídio de mulheres representava 11,6\% em 2015, passando a 12,5\% em 2016 e 13,6\% em 2017. Tal investigação evidenciou, ainda, um crescimento de 41\% dos feminicídios entre 2008 a 2017, somando cerca de 2.677 mulheres vítimas de morte em razão do gênero na Argentina (LEGRAND et al, 2020, p. 06).

Em regra, configuram-se como os agressores pessoas com quem as vítimas mantêm vínculo sentimental ou familiar. O Ministério Público Argentino demonstrou que, no primeiro semestre de 2020, estes representaram cerca de $88,9 \%$ das pessoas que cometeram feminicídios (ARGENTINA, 2020). Ademais, verifica-se que a maioria dos casos ocorre no lar das vítimas, cerca de $71 \%$ dos casos em 2017 e 66\% em 2018, ocasião em que 58\% dessas mulheres estavam em convívio direto com o assassino (LEGRAND et al, 2020, p. 07).

Além disso, o estudo promovido pela FRIEDRICH-EBERT-STIFTUNG, traz, ainda, alguns dados relacionados ao cenário argentino em que estáo envoltos às vítimas e os assassinos (LEGRAND et al, 2020, p. 06):

Em 39\% dos casos, as vítimas de feminicídios pertenciam à faixa etária de 18 a 44 anos. Em 2017-2018, um total de 22 vítimas eram migrantes, 21 eram trabalhadoras sexuais, 17 se encontravam grávidas, 11 tinham alguma deficiência e 3 pertenciam a povos originários. 9 vítimas pertenciam à população travesti/ trans. No que diz respeito aos agressores, repete-se a prevalência da faixa etária de 18 a 44 anos (2017-2018). Nesses anos, um total de 35 autores (6,5\%) eram membros das forças de segurança ou pertenciam a uma agência de segurança privada. Vale sublinhar que a incidência pode ser maior, já que em muitos casos a ocupação do agressor é desconhecida. 
Cumpre destacar, ainda, que esses números podem não refletir a real situação, tendo em vista que muitas mulheres acabam não denunciando as violações sofridas ou as mortes destas não são contabilizadas como feminicídios.

Outrossim, a maioria destes dados refletem uma situação argentina anterior a pandemia da Covid-19, situação em que houve "lockdown" e muitas mulheres tiveram que promover o isolamento social junto aos seus agressores (BBC, 2020). A orientação das autoridades sanitárias que promoveram o confinamento, medida fundamental ao enfrentamento ao Covid-19, foi responsável por um aumento exponencial da violência de mulheres em diversos países (BARBOSA et al, 2020, p. 04).

Diante a situaçáo de pandemia, os números de crimes de gênero aumentaram $15 \%$ no primeiro semestre de 2020, em relação ao mesmo período do ano anterior, conforme a Unidad Fiscal Especializada de Violencia contra las Mujeres (UFEM, 2020, p. 11). Além disso, somente nos primeiros meses de 2020, foram registrados cerca de 160 feminicídios, tendo sido 97 deles no período em que ocorria a quarentena (GZH MUNDO, 2021). Tais números refletem apenas parte do período pandêmico, podendo o cenário de violaçôes às mulheres ser muito pior atualmente.

Consequentemente, verifica-se, frente aos dados apresentados, que a sociedade argentina demonstra ter enraizado um sistema patriarcal que reflete um cenário de violência e perigo à mulher (LIMA, 2017, p. 06). Apesar das grandes mobilizaçóes de movimentos femininos, nos quais a luta por maior visibilidade da violência de gênero encontra-se em foco, o país vive um paradoxo em que embora possuam avanços legislativos e governamentais, os números não param de crescer (CARDOSO, 2018). Isto traz a perspectiva de uma necessidade vital de maior mobilização estatal no combate do que a ONU classifica como "pandemia do feminicídio e da violência a mulheres" (ONU MULHERES, 2020).

\section{Legislaçáo de proteçáo contra violência de gênero na Argentina}

Quais são os avanços legislativos citados no parágrafo anterior? Para que seja possível compreender o caminho do Poder Legislativo Argentino na tentativa de erradicar a violência de gênero no país, esta seção abordará as normas de acordo com os anos em que estas foram sendo publicadas, como uma linha do tempo.

A partir dos anos 1980, com o fim da ditadura militar argentina (1976-1983), o processo de redemocratização contou com a grande participação de diversos movimentos sociais no país, em especial os movimentos de mulheres e feministas (DE CAMPOS et al, 2011, p. 17). Tais movimentos conquistaram a ratificação de importantes documentos internacionais para o fim da violência de gênero na Argentina. Como exemplo, a ratificação em 1985 da "Convenção para a Eliminação de Todas as Formas de Discriminação Contra a Mulher" e em 1996 da "Convenção Interamericana para Prevenir, Punir e Erradicar a Violência contra a Mulher" (DE CAMPOS et al, 2011, p. 17).

Em 1992, através do Decreto Nacional no 1426, houve a criação de um chamado "Mecanismo de Gênero" - o qual busca a formulação, implementação e acompanhamento das políticas de gênero no país. Neste, o Conselho Nacional das Mulheres (CNM) foi criado com o objetivo de fiscalizar e trabalhar pelo cumprimento dos acordos internacionais ratificados, além 
de elaborar planos e programas para a equidade de gênero (DE CAMPOS et al, 2011, p. 17).

Historicamente, dentre os países que fazem parte do MERCOSUL, a Argentina foi o primeiro a aprovar uma legislação que possuía o objetivo de enfrentar a violência doméstica. A Lei 24.417/1994, intitulada "Ley de Protección contra la Violencia Familiar", possui como resumo a proteçáo contra a violência à toda pessoa que sofre maltrato físico ou psíquico por parte de um dos integrantes do grupo familiar. A lei permanece vigente no país ainda hoje (DE CAMPOS et al, 2011, p. 17).

Um fato interessante é a mudança no cenário normativo da Argentina no ano de 2009 ocasionada pela aprovação da Lei Maria da Penha no Brasil em 2006 (DE SOUZA, 2013, p. 9). Tal como um espelho, o país promulgou a "Ley de Protección Integral para Prevenir, Sancionar, y Erradicar la Violencia Contra las Mujeres en los Ámbitos en que Desarrollen sus Relaciones Interpersonales" no 26.485/09 a qual objetiva à mulher uma vida sem violência e define seus direitos básicos e garantías mínimas nos procedimentos (ARGENTINA, 2009). Entretanto, diferente do Brasil, a legislação argentina não previu dispositivo no Código Penal para a sanção de violência de gênero (DE CAMPOS et al, 2011, p. 17).

Foi somente no ano de 2012 que o legislativo argentino, através da Ley no 26.791 substituiu o inciso I do Artigo 80 do Codigo Penal de La Nación Argentina positivando a pena agravada para morte por ascendente, descendente, cônjuge, ex cônjuge ou pessoa que mantinha relação (com ou sem convivência) (ARGENTINA, 2012). Ainda, incorporou o inciso XI o qual aborda a prisão perpétua à morte por violência de gênero (ARGENTINA, 2012).

Pôde-se perceber que, durante as pesquisas sobre as mudanças levadas pela Lei 26.791/12 à positivação penal da Argentina, na maioria dos artigos e notícias os autores e autoras tratam a substituição do inciso I e incorporação do XI como uma integração da figura do "feminicídio". Todavia, o termo não é utilizado em nenhum artigo do código.

Continuadamente, no ano de 2019 foi promulgada a "Ley Micaela" de no 27.499. Esta permanece vigente e versa sobre a obrigatoriedade de qualificação de todos os profissionais que exerçam função pública quanto à matéria de gênero e violência contra a mulher (ARGENTINA, 2019). Interessante aqui fazer uma crítica à maneira como agiram os funcionários no caso Úrsula Bahillo: delegacia com portas fechadas e a demora na tomada de decisóes que poderiam ter prolongado sua vida.

Por fim, no ano de 2020, foi declarado, através da Ley 15.173/20, estado de emergência por violência de gênero na província de Buenos Aires (AR). Como fundamento, tem-se que somente nos três primeiros meses do supracitado ano foram registrados 86 feminicídios no país (ARGENTINA, 2020). A referida lei, dentre diversas disposiçôes, permite a contratação de hospedagens a fim de funcionarem como abrigos temporários das vítimas de violência quando a permanência em casa for uma ameaça, visa fortalecer o Judiciário com o objetivo de construir alertas precoces e garantir medidas de proteçáo, e projeta promover campanha de conscientizaçáo, bem como qualquer ação que leve à "prevenção, assistência, punição e erradicação da violência de gênero na Província de Buenos Aires" (ARGENTINA, 2020).

As normas aqui citadas exprimem as principais legislaçóes que dispóem sobre a violência de gênero na Argentina. Não obstante, ainda assim se percebe que não são tão eficazes, tanto é que a presente investigação apresenta um caso posterior a estes institutos. 
A morte de Úrsula Bahillo, além da inquietação do movimento feminino, levou a deputada Carolina Gaillard, presidente da Comissão de Legislação Criminal, a apresentar um projeto de lei que propóe uma modificação no Código Penal. Sua motivação veio da denúncia de violação da medida protetiva por Martínez e sua impunibilidade. O projeto visa não só aumentar a pena já prevista para o crime de violação de restrição penal (de 15 dias à um ano para três à cinco anos de reclusão), mas também agravar as sanções aos funcionários públicos omissos e àqueles que atrasarem na assistência à vítima (RIGGIO, 2021).

Pelo exposto por toda a presente seção, observa-se que a luta contra violência de gênero na Argentina, assim como tem grande histórico, permanecerá por alguns anos. Os institutos sequer foram capazes de mudar a visão em relação ao valor da vida de uma mulher. Estas aparentemente permanecem inferiores, tanto à vista dos seus agressores, quanto do Estado.

\section{A morte de mulheres como consequência da omissáo estatal}

Figura 2: "Paren de matarnos"

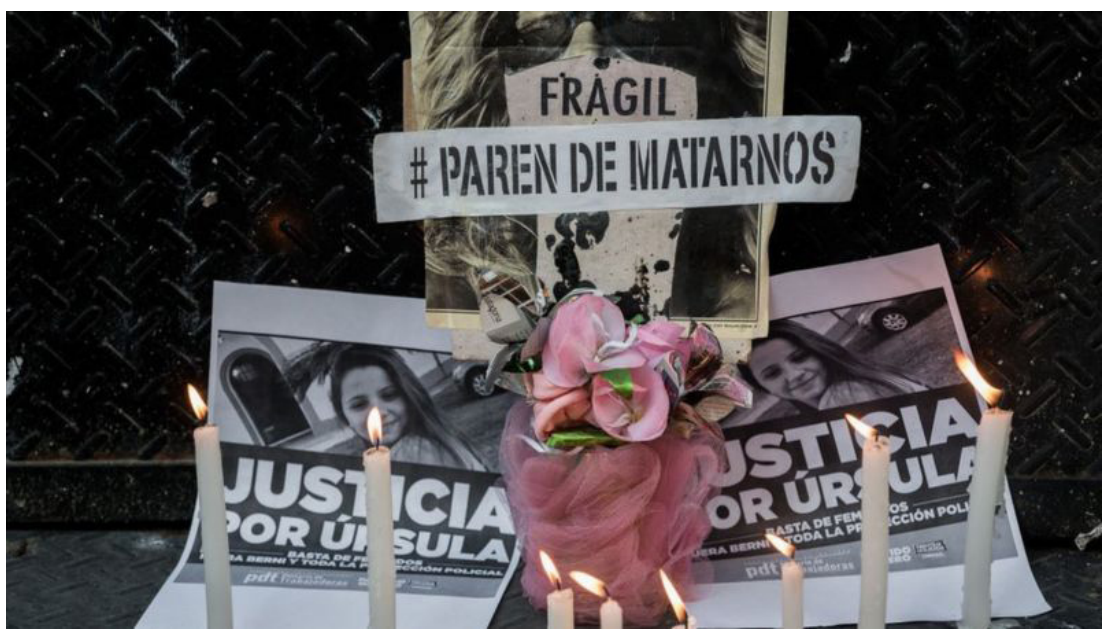

Fonte: BBC, 2021

Diante dos acontecimentos que originaram a morte de Úrsula, um questionamento muito importante tem sido levantado diariamente pelas mulheres: por que o Estado não toma as medidas necessárias para proteger às vítimas de violência doméstica? $\mathrm{O}$ primeiro conselho que uma mulher recebe de alguém próximo após contar sobre alguma situação de violência vivida é "você tem que fazer a denúncia", mas como observado no caso em questáo, recorrer às autoridades não foi suficiente. A circunstância torna-se ainda mais alarmante quando observado o número de casos de feminicídios cometidos por policiais, profissionais que integram o sistema do Estado e os quais, teoricamente, deveriam trazer proteção à sociedade.

Dados apontam que, na Argentina, uma em cada cinco mulheres são mortas por companheiros ou ex-companheiros policiais (PAIXÃO, 2021). Além do mais, familiares das vítimas chegaram a denunciar à imprensa que dentro da corporação policial existe certa cumplicidade, na qual destacam-se açóes realizadas por esses agentes para encobrir vestígios de crimes cometidos por seus colegas (CENTENERA, 2021).

Como já citado nesta pesquisa, a Argentina chegou a criar medidas que objetivam a prevenção de casos de violência doméstica, tal qual a Lei Micaela, promulgada em 2019, que 
estabelece curso de capacitação obrigatória, aos agentes públicos, sobre violência de gênero (ARGENTINA, 2019). O país inclusive foi o primeiro do Mercosul a estabelecer normas que tratam especificamente de violência doméstica, medida que logo foi tomada pelos demais países do grupo (DE CAMPOS et al, 2011, p. 18).

Contudo, ao analisar os dados apresentados, observa-se que tais medidas ainda náo apresentaram efeitos, visto que os crimes continuam a ser cometidos diariamente e a maior causa de morte entre as mulheres argentinas ainda é o feminicídio. Importante destacar, ainda, que a Argentina apresenta números alarmantes de repressão policial, e esse cenário também é fator importante para compreender os dados relacionados aos casos de violência doméstica cometidos por esses agentes no país (PAIXÃO, 2021).

Isto posto, é essencial ressaltar, ainda, a atuaçáo do judiciário argentino, que também deve ser responsabilizado pela morte de Úrsula, e de tantas outras mulheres vítimas de feminicídio. Como explicitado anteriormente, o agressor já havia praticado agressóes a outras mulheres e chegou a ser afastado em 2018, mas já em 2020 retornou às suas atividades. E mesmo quando o número de agressóes passou a ser alarmante e cumulativo, tudo que recebeu foi uma licença psiquiátrica, sequer chegou a ser detido. Ademais, a vítima chegou a realizar a denúncia inúmeras vezes, porém, todas foram rejeitadas pelo juiz de paz que cuidava do caso, com a justificativa de que o agressor não apresentava perigo.

Dessa maneira, é mais do que necessário entender que a morte de Úrsula foi consequência da omissão do Estado, que falhou em proteger uma vítima de violência doméstica, falhou em punir os agressores e, ainda, falhou em aplicar corretamente as leis e medidas criadas para prevenir, investigar e combater a violência de gênero.

De acordo com informaçôes do Instituto MuMaLa, do total de feminicídios praticados em janeiro na Argentina, 25\% possuíam denúncias prévias, 17\% dos casos possuíam alguma medida de restrição e $12 \%$ dos homens que praticaram o crime faziam parte da Força de Segurança (PAIXÃO, 2021). Todo esse cenário preocupante impulsionou uma série de movimentos que clamam por uma reforma no sistema judiciário e policial e se intensificaram com a repercussão do caso de Úrsula.

A Doutora em Direito Marisa Herrera é uma das mais importantes ativistas que luta pela causa feminista no país, e destaca que "Criar novos tribunais, mas que eles sejam compostos por homens machistas não muda nada" (PAIXÃO, 2021). A fala de Herrera é essencial para a compreensão de que a mera criação de leis, conselhos e tribunais náo é suficiente se o Estado de fato náo se empenhar em minimizar o machismo e a misoginia dentro de suas instituiçóes, bem como em tomar iniciativas que possam proteger efetivamente as vítimas desse tipo de violência.

\section{A deturpaçáo da ética frente o machismo estrutural que permeia a sociedade e as instituiçóes}

Os fatos trazidos no estudo demonstram de que as apreensóes culturais machistas e patriarcais concernentes na sociedade latina, em especial, na Argentina, promovem grave recorrência de violências contra as mulheres frente a omissão estatal, resultando em numerosos casos de feminicídios brutais, como o de Úrsula Bahillo.

O caso por ora estudado traz à tona uma característica que piora ainda mais o cenário 
violentador das mulheres: a invisibilidade. Tal traço demonstra como as violaçôes de vidas femininas são encaradas como natural, normal e estão enraizadas culturalmente na sociedade e nas instituiçóes que deveriam primar pelos direitos de grupos vulneráveis, promovendo injustiça e impunidade (MOTTA, 2017, p. 13).

Verifica-se, assim, uma persistência da práxis jurídica e do próprio estado em negar garantia efetiva de direito às mulheres, situaçáo em que desconsideram um recorte de gênero no trato das violências nas instituiçóes estatais (CHAI et al, 2019, p. 647). Isto, pois, o direito latino, em suma, é masculino, "condicionando seu conteúdo por interesse masculino e modo de sentir masculino" (RADBRUCH apud CHAI et al, 2019, p. 647).

Como Rodbrunch expressou, o direito sempre quis excluir as mulheres, não só momentaneamente, mas para prejudicar sua participação futura ativa, situaçáo em que se perpetuava uma concepção patriarcal machista nas relaçóes estatais (CHAI et al, 2019, p. 647). Diante disto, a apreensão de normalidade da violência contra mulher reflete a forma como nossa sociedade lida com a situação, e isso acaba por negar punidade a criminosos como Matías Martínez, assassino de Úrsula Bahillo.

Ao lidar com violência de gênero deve-se levar em conta que este é um fenômeno complexo e múltiplo, devendo ser compreendido frente a diversos fatores sociais, históricos, culturais e subjetivos (GUIMARÃES; PEDROZA, 2015, p. 259). Entretanto, o estudo desses fatores não são percebidos nas ações estatais.

Em contrapartida, o que se vê é a injustiça persistir, onde o Estado passa a negar voz àqueles que são afetados nos processos de asseguração de direitos e impedidos de criar arenas democráticas em que as reivindicaçôes possam ser avaliadas e sequer contempladas (MOTTA, 2017, p. 35). E ao invés de se observar um ambiente democrático, em que avalie todos os aspectos subjetivos que violam as mulheres, há uma negação de processos que primam pela paridade de participação (MOTTA, 2017, p. 35).

Nesse contexto, as atitudes estatais, principalmente, por meio do judiciário e das forças policiais, trazem em seus ínfimos resquícios do patriarcado perpetuador da violência, os quais são graves instrumentos violadores da própria ética jurídica e profissional que deveria guiar os julgamentos e tratamentos de litígios vulnerabilizantes.

A ética, conforme afirma Pertielle:

É a reflexão, é a análise da moral que permeia uma cultura. É o conjunto de exercícios que são praticados no sentido de compreender até que ponto determinada moral de fato está guiando um grupo de pessoas para o melhor que seu potencial autoriza. E nesse contexto, tem-se que a moral é temporal e diz respeito às sociedades individualizadas (PERTIELLE et al, 2019, p. 13).

Até este ponto, já se tem observado que a sociedade argentina, e principalmente o Estado Argentino, não se mostra ético no contexto de violência contra à mulher. Porém, essa análise é intuitiva, isto é, apesar do conceito ser de difícil explicação, cada ser em seu interior sabe o que é ser ético. Ricoeur (1990, p. 3) bem caracteriza o termo quando menciona ser a ideia de "uma vida consumada sob o signo das ações estimadas como boas". Foram boas as açóes (e omissóes) sociais e estatais no caso de Úrsula?

Ora, apesar do grande movimento de mulheres em luta contra a violaçấo de suas vidas, os números de agressões continuam a subir. Enquanto a mente social não sofrer transformação 
e possuir o real entendimento da gravidade da situação, a legislação de nada adiantará. Esta afirmação é ainda comprovada quando se traz a estudo o preâmbulo da Constitución de la Nación Argentina.

Sendo a ética a análise da moral que permeia uma cultura e o conjunto de exercícios praticados para compreender o que de fato direciona um grupo de pessoas, pode-se ter a constituição como guia e mentora da ética argentina. Assim, seu preâmbulo dispóe que, a Constitución de la Nación Argentina foi estabelecida com o objetivo de "estabelecer a uniáo nacional, fortalecer a justiça, consolidar a paz interior, providenciar a defesa comum, promover o bem-estar geral e garantir os benefícios da liberdade" (ARGENTINA, 1853). Logo, viabilizar julgamentos e políticas públicas pautadas em apreensôes morais, em regra machistas, ao lidar com violência de gênero, corrobora com a incidência de mais violaçóes e deturpa a imagem ética e ilibada como garantidor de direitos do Estado.

Assim, questóes como a morosidade do sistema estatal, que gera a vivência contínua da mulher em um ambiente de "abusos e violências, sendo maltratada e coagida a retirar sua denúncia e a manter-se calada, pois, se encontra em uma situação de vulnerabilidade”, promove o que podemos chamar de violência de gênero estatal (CHAI et al, 2019, p. 648).

Um exemplo de tal situação é o caso de Úrsula Bahillo, na qual a omissão e morosidade estatal promoveu a sua morte. Isso dado às reiteradas denúncias de Bahillo e a desatenção das autoridades policiais e judiciais, diante do histórico do assassino de acusaçóes de violência e processos administrativos na unidade policial, não houve apoio das autoridades locais e quiçá atenção emergencial por parte do judiciário (LLORENTE, 2021).

Da mesma maneira, ocorreu o caso de Paola Tacacho que configurou como mais uma vítima da violência estatal (BBC, 2020). Tacacho apresentou cerca de 13 denúncias nos cinco anos de perseguição vivida pelo seu assassino (BBC, 2020). Entretanto, o Estado a desassistiu e não promoveu sequer coação frente ao cumprimento das medidas de restrição, com base no argumento de "náo haver resultados suficientes" (BBC, 2020).

No mesmo sentido, a falta de auxílio especializado policial, a violência das forças policiais e seus abusos de autoridade promovem maior vulnerabilização dessas mulheres, causando os chamados "feminicídios de uniforme" (PAIXÃO, 2021). Isto, pois, quando se verifica que os elementos de repressão estatal e a violência machista e patriarcal configuram características em um mesmo indivíduo, se potencializa a violência de gênero (VERDÚ aput PAIXÃO, 2021).

Questáo corroborada pelos números levantados: cerca de um a cada cinco feminicídios são cometidos por agentes de segurança pública na Argentina (PAIXÃO, 2021). Em 90\% dos casos os crimes são realizados com o próprio armamento da instituição (PAIXÃO, 2021). Só em janeiro de 2021, 12\% dos feminicídios na Argentina foram cometidos por forças policiais (UFEM, 2021, p. 17).

Ressalta-se, ainda, que as vítimas são, em regra, além de desassistidas, desacreditadas judicialmente, e quando os agressores são membros das forças de segurança isso se intensifica. Isto, pois como afirma Verdú “a justiça e as forças de segurança andam juntas”, e como exprime:

Não faz diferença uma placa dizendo 'Delegacia da Mulher' quando, no final das contas, quem atende é um policial, com a mesma conduta que em qualquer outra delegacia. Também há o vínculo próximo entre o poder judicial e as forças de segurança, que, tecnicamente, são seus 
auxiliares. A lógica dos tribunais parte de acreditar nos uniformizados (PAIXÃO, 2021).

À face do exposto, o que vemos são graves violações da ética profissional dos servidores judiciais e policiais, que deveriam configurar os primeiros garantidores de direitos. Visto que a moral e a ética, nestas profissôes, estão comprometidas com valores que promovem a dignificação e respeito das pessoas em suas diferenças e potencialidades (SOARES, 2015). Conjuntura em que os princípios éticos e morais que devem ser inerentes a esses profissionais, objetivam atender os desígnios da função social e do respeito ao ser humano, são visivelmente desrespeitados por um uma cultura patriarcal enraizada nos agentes estatais (SOARES, 2015).

\section{Consideraçóes finais}

O desenvolvimento do presente artigo buscou compreender quais os fatores primordiais para o alarmante número de feminicídios ocorridos na Argentina, trazendo como ponto de referência o caso de Úrsula Bahillo. Por meio da análise dos temas, observa-se que o papel do Estado em prevenir e combater esse tipo de crime é primordial, visto que a sua omissão gerou uma série de acontecimentos que contribuíram para o assassinato da jovem de 18 anos.

Além do mais, destaca-se que o combate à violência doméstica não deve incluir somente a criação de medidas sem que haja, de fato, a aplicação destas dentro da Administração Pública argentina, uma vez que o país chegou a ser pioneiro no que se refere ao estabelecimento de leis sobre o combate ao crime de gênero. Ou seja, esse pioneirismo não impediu que o país apresentasse um cenário tão aterrorizante às mulheres, as quais são agredidas e mortas mesmo quando buscam a proteção que deveria ser provida pelo Estado.

Tal conjuntura acarreta em uma série de problemáticas, como o receio das vítimas em realizar a denúncia, o descrédito das medidas criadas pelo Estado e o sentimento de impunidade em relação aos agressores. Já é bastante difícil para as vítimas terem a coragem de se abrir sobre as violências sofridas, e o fato de tantas mulheres serem mortas na esperança de que tenham alguma proteção estatal silencia ainda mais aquelas que podem futuramente acabar na mesma situaçáo.

Nesse sentido, foi destacada a ideia distorcida que os cidadáos e principalmente os funcionários públicos do país possuem do que é ser ético. Isso pois, apesar de haver instrução dos objetivos constitucionais argentinos e uma legislação precursora no combate à violência contra a mulher, os índices permaneceram altos a ponto de ter sido instituído Estado de Emergência na província principal, Buenos Aires. Deturpação essa que pode ser considerada histórica, pois advém da colonização do país, e é bem identificada no meio social argentino. Se assim não fosse, os números seriam bem menores e Ursula Bahillo estaria viva.

\section{Referências}

ARGENTINA. Constitución de la Nación Argentina (1853). Disponível em: <https://siteal.iiep. unesco.org/pt/bdnp/897/constitucion-nacion-argentina>. Acesso em: 13 jul. 2021.

ARGENTINA. Ley 15.173 de 27 de mayo de 2020. Disponível em: <https://normas.gba.gob. ar/ar-b/ley/2020/15173/212761>. Acesso em: 12 abr. 2021.

ARGENTINA. Ley 27.499 de 10 de enero de 2019. Ley Micaela de capacitación obligatoria en 
género para todas las personas que integran los tres poderes del Estado. Disponível em: <https:// www.argentina.gob.ar/normativa/nacional/ley-27499-318666/texto>. Acesso em: 11 jul. 2021.

ARGENTINA. Ley $N^{\circ} 26.485$ de 01 de abril de 2009. Ley de Protección Integral para prevenir, sancionar y erradicar la violencia contra las mujeres en los ámbitos en que desarrollen sus relaciones. Disponível em: <https://siteal.iiep.unesco.org/sites/default/files/sit_accion_files/siteal_ argentina_0859.pdf>. Acesso em: 12 jul. 2021.

ARGENTINA. Ley no 26. 791 de 14 de noviembre de 2012. Disponível em: <http://servicios. infoleg.gob.ar/infolegInternet/verNorma.do?id=206018>. Acesso em: 12 jul. 2021.

ARGENTINA. Primer Semestre de 2020 - Comparativo entre periodos: prévio al aislamiento social, preventivo e obligatorio (01-01 al 19-03) e durante el mismo 20-03 al 30-06_comparativo con mismo periodo año de 2019. Disponível em: <https://www.mpba.gov.ar/files/ content/Informe_de_Femicidios_PrimerSemestre2020.pdf>. Acesso em: 11 jul. 2021.

ARGENTINA. Registro penal de delitos vinculados o atravesados por la violencia familiar y de género. Disponível em: <https://www.mpba.gov.ar/infoviolenciafamiliar>. Acesso em: 11 jul. 2021.

BARBOSA, Jeanine Pacheco Moreira; LIMA, Rita de Cassia Duarte; SANTOS, Gabriela de Brito Martins; LANNA, Solange Drumond; e ANDRADE, Maria Angélica Carvalho. Interseccionalidade e outros olhares sobre a violência contra mulheres em tempos de pandemia pela covi-19. Disponível em: <https://preprints.scielo.org/index.php/scielo/preprint/view/328>. Acesso em: 11 jul. 2021.

BBC. Femicidio de Paola Tacacho | "La mató el Estado": indignación en Argentina por la muerte de una profesora de inglés apuñalada en plena calle por un exalumno que la acosó durante 5 años. Disponível em: <https://www.bbc.com/mundo/noticias-america-latina-54786756>. Acesso em: 12 jul. 2021.

BBC. País por pais: o mapa que mostra os trágicos números dos feminicídios na América Latina. Disponível em: <https://www.bbc.com/portuguese/internacional-38076091>. Acesso em: 11 jul. 2021.

CARDOSO, Ana Flávia da Cruz Montemor. O Feminicídio na América Latina: um estudo de caso da Argentina. Disponível em: <https://ovisto.ufsc.br/2018/11/23/o-feminicidio-naamerica-latina-um-estudo-de-caso-da-argentina/>. Acesso em: 11 jul. 2021.

CEGATTI, Amanda Carolina. Violência de Gênero contra as Mulheres e Cultura Politica no Brasil e na Argentina. Disponível em: <https://lume.ufrgs.br/handle/10183/175314>. Acesso em: 11 jul. 2021.

CENTENERA, Mar. Assassinato de mäe e filha na Argentina acende alerta sobre a violência contra mulher na quarentena. Disponível em:<https://brasil.elpais.com/sociedade/2020-03-31/ assassinato-de-mae-e-filha-na-argentina-acende-alerta-sobre-a-violencia-contra-mulher-naquarentena.html>. Acesso em: 11 jul. 2021.

CENTENERA, Mar. Denunciou o companheiro 18 vezes e foi assassinada. O feminicidio que coloca a polícia argentina na mira. Disponível em: <https://brasil.elpais.com/ internacional/2021-02-11/denunciou-o-companheiro-18-vezes-e-foi-assassinada-ofeminicidio-que-coloca-a-policia-argentina-na-mira.html?ssm=whatsapp $>$. Acesso em: 07 jul. 
2021.

CHAI, Cassius Guimarães; SANTOS, Jéssica Pereira dos; CHAVES, Denisson Gonçalvez. Violência Institucional Contra a Mulher: o poder judiciário, de pretenso protetor a efetivo agressor. Disponível em: <https://periodicos.ufsm.br/revistadireito/article/view/29538>. Acesso em: 12 jul. 2021.

CIJUR. El fiscal pidió la prisión preventiva del policia acusado de matar a Úrsula Babillo en la localidad de Rojas. Disponível em: <https://cijur.mpba.gov.ar/novedad/2489\#>. Acesso em: 07 jul. 2021.

DE CAMPOS, Carmen; MARRA, Carolina; PASINATO, Wânia. Indicadores sobre violência doméstica baseada em gênero no Mercosul. Disponível em: <http://www.senado.leg.br/comissoes/ documentos/SSCEPI/DOC\%20VCM\%20112.pdf>. Acesso em: 12 jul. 2021.

DELFINO, Emilia. El feminicidio de Úrsula Bahillo expone por qué fallan las politicas contra la violencia e interpela a todos los poderes del Estado. Disponível em: <https://cnnespanol.cnn. com/2021/02/17/feminicidio-ursula-bahillo-argentina-femicidio-emilia-delfino/> Acesso em: 07 jul. 2021.

DE SOUZA, Suellen. Leis de combate à violência contra a mulher na América Latina: uma breve abordagem histórica. Disponível em: <http://snh2013.anpuh.org/resources/ anais/27/1371348947_ARQUIVO_TextoAnpuhNatalSuellen.pdf> Acesso em: 12 jul. 2021.

GUIMARÃES, Maisa Campos; PEDROZA, Regina Lucia Sucupira. Violência Contra Mulher: Problematizando definiçôes teóricas, filosóficas e jurídicas. Disponível em: <https://www.scielo.br/ scielo.php?pid=S0102-71822015000200256\&script=sci_arttext>. Acesso em: 12 jul. 2021.

GZH MUNDO. Homicídio de jovem pelo ex-namorado policial choca a Argentina. Disponível em: <https://gauchazh.clicrbs.com.br/mundo/noticia/2021/02/homicidio-de-jovem-pelo-exnamorado-policial-choca-a-argentina-ckkyopdc502ag01i1q1n1m3tl.html>. Acesso em: 11 jul. 2021.

LEGRAND, Denisse; PORTERIE, Sidonie; e MORIN, Stephanie. Panorama e Desafios da Violência Contra as Mulheres em três paises da América Latina: Brasil, Uruguai e Argentina. Disponível em: <http://library.fes.de/pdf-files/bueros/brasilien/17100.pdf>. Acesso em: $11 \mathrm{abr}$. 2021.

LIMA, Amanda Gabriela Gomes de. "Nenhuma a Menos": o movimento feminista e o enfrentamento ao feminicídio na América Latina. Disponível em: <https://www. en.wwc2017.eventos.dype.com.br/resources/anais/1539016234_ARQUIVO_ AmandaGabrielaGomesdeLima.pdf >. Acesso em: 11 jul. 2021.

LLORENTE, Analía. Quién era Úrsula Bahillo, la joven asesinada a puñaladas por su exnovio policia a pesar de las múltiples denuncias. Disponível em: <https://www.bbc.com/mundo/ noticias-56093328>. Acesso em: 07 jul. 2021.

LUCOTTI, Francisco. Otra vez la polícia: furia en Argentina por un nuevo feminicidio a manos de unagente. Disponível em: <https://mundo.sputniknews.com/20210212/otra-vez-la-policiafuria-en-argentina-por-un-nuevo-femicidio-a-manos-de-un-agente- $1102469850 . h t m l>$. Acesso em: 07 jul. 2021. 
MOTTA, Maria Carolina Carvalho. Invisibilidades e Persistências: Politicas Públicas de combate à Violência contra as Mulheres (Brasil e Argentina). Disponível em: <https://repositorio.unb.br/ bitstream/10482/23552/1/2017_MariaCarolinaCarvalhoMotta.pdf>. Acesso em: 11 jul. 2021.

ONU MULHERES. Relatora da ONU defende ação urgente para erradicar "pandemia" de feminicídio. Disponível em: <https://news.un.org/pt/story/2020/11/1733822>. Acesso em: 11 jul. 2021.

PAIXÃO, Fernanda. Feministas propóem reforma estrutural do Judiciário argentino. Disponível em: <https://www.brasildefato.com.br/2021/04/06/patriarcal-e-elitista-judiciario-argentinotera-reforma-pautada-por-feministas>. Acesso em: 10 jul. 2021.

PAIXÃO, Fernanda. Um em cada cinco feminicídios é provocado por agentes de segurança na Argentina. Disponível em: <https://www.brasildefato.com.br/2021/02/26/um-em-cada-cincofeminicidios-e-provocado-por-agentes-de-seguranca-na-argentina>. Acesso em: 13 jul 2021.

PAIXÃO, Fernanda. Um em cada cinco feminicídios é provocado por agentes de segurança na Argentina. Disponível em: <https://www.brasildefato.com.br/2021/02/26/um-em-cada-cincofeminicidios-e-provocado-por-agentes-de-seguranca-na-argentina>. Acesso em: 09 jul. 2021.

PERTILLE, Thais Silveira; PERTILLE, Marcelo. Compreendendo a pedagogia libertária como marco no ensino jurídico para o fortalecimento dos direitos humanos: em busca do compromisso ético com as questôes de gênero. Disponível em: <https://ojs.sites.ufsc.br/index.php/capturacriptica/ article/view/4065/3260>. Acesso em: 12 jul. 2021.

RICOEUR, Paulo. Ética e Moral. Textos Clássicos: LUSOFIA. Corvilhã, 2011. Disponível em: <http://www.educaretransformar.net.br/wp-content/uploads/2017/04/\%C3\%89TICA-EMORAL-CONCEITO.pdf>. Acesso em: 13 jul. 2021.

RIGGIO, Pablo. Tras el feminicidio de Úrsula, diputadas presentaron un proyecto de ley para que sean detenidos los agresores que violen una perimetral. Disponível em: <https://www.infobae. $\mathrm{com} /$ sociedad/2021/02/11/tras-el-femicidio-de-ursula-diputadas-presentaron-un-proyectode-ley-para-que-sean-detenidos-los-agresores-que-violen-una-perimetral/>. Acesso em: 12 jul. 2021.

SOARES, João Thiago Aureliano Pedosa. Ética e moral: influência nas corporaçóes policiais militares. Disponível em: <https://bityli.com/G2meu> . Acesso em: 13 jul. 2021.

TELAM. Três días antes del feminicidio Úrsula denunció que Martínez la había amenazado de muerte. Disponível em: <https://www.telam.com.ar/notas/202102/544344el-policia-le-habia-dicho-a-rsula-que-no-se-meta-con-su-familia-porque-andan-en-la-pesada. html>. Acesso em: 08 jul. 2021.

UFEM, Unidad Fiscal Especializada de Violencia contra las Mujeres. Homicidios dolosos de mujeres y femicidios en la Ciudad Autónoma de Buenos Aires durante el Aislamiento Social Preventivo Obligatorio (ASPO). Disponível em: <https://www.mpf.gob.ar/ufem/files/2020/08/ UFEM-Relevamiento-del-estado-de-las-investigaciones-por-muertes-violentas.pdf $>$. Acesso em: 11 jul. 2021.

UFEM, Unidad Fiscal Especializada de Violencia contra las Mujeres. Relevamiento del estado de las investigaciones por muertes violentas de mujeres y otras identidades femeninas en la Ciudad Autónoma de Buenos Aires (años 2015-2019). Disponível em: <https://www.mpf.gob.ar/ufem/ 
files/2021/03/UFEM-Informe-estad\%C3\%ADstico_CABA2015-2019.pdf>. Acesso em: 11 jul. 2021.

VILLALBA, Gisela Paola. La violencia contra la mujer en la legislación Argentina. La otra cara de la pandemia. Disponível em: <https://bityli.com/9sLIO>. Acesso em: 12 jul. 2021. 